\title{
KURSUS ANALISIS PEMBELAJARAN ASUHAN KEBIDANAN II PROGRAM STUDI D3 KEBIDANAN UNIVERSITAS ISLAM MADURA
}

\author{
Learning Analysis Courses Of Midwifery Care II Study Program D3 Of Midwifery \\ Islamic University Of Madura
}

\author{
Layla Imroatu Zulaikha ${ }^{1}$, Yulia Paramita ${ }^{2}$
}

1. Universitas Islam Madura

\section{Riwayat artikel}

Diajukan: Agustus 2020

Diterima: September 2020

\section{PenulisKorespondensi:}

- Layla Imroatu Zakiyah

- Universitas Islam

Madura

- aylaathariz@gmail.c $\underline{\text { om }}$

\section{Kata Kunci: \\ Learning Analysis \\ Courses, Midwifery Care \\ II}

\section{Abstrak}

Latar Belakang : Kebidanan perawatan II adalah mata pelajaran wajib dalam program studi D3 kebidanan islam universitas Madura, karena berhubungan langsung dengan tugas utama bidan, adalah menghadiri kelahiran. Untuk itu, proses pembelajaran perawatan kebidanan II membutuhkan perhatian khusus, baik dalam hal teori maupun praktik. Tujuan : Tujuan penelitian ini untuk menganalisis kursus pembelajaran perawatan kebidanan II. Metode : Desain yang digunakan dalam penelitian ini adalah kualitatif deskriptif. Penelitian yang akan dilakukan dalam dari satu studi kasus dengan satu karakteristik (satu lokasi). Responden dalam penelitian ini meliputi mahasiswa, kuliah, dan kepala program studi. Dalam penelitian ini ada tiga jenis analisis pengumpulan data. Validitas teknis data dengan sumber triangulasi dan metodis. Teknik yang digunakan dalam proses analisis dengan menggunakan model analisi interaktif. Hasil : (1) rencana pembelajaran dilakukan secara optimal, (2) pelaksanaan pembelajaran menggunakan berbagai metode pembelajaran, (3) evaluasi pembelajaran adalah tes menengah yang dinilai secara optimal, tes akhir dan uji fase, (4) contrains yang dihadapi dalam proses pembelajaran yang merupakan minat siswa dalam pembelajaran kurang, sedangkan bagaimana evercome dalam proses pembelajaran adalah komunikasi dua arah untuk menentukan dificulty dan memberikan lebih banyak waktu untuk diskusi. Kesimpulan : proses pembelajaran secara keseluruhan kurang optimal, karena kurangnya minat siswa dalam belajar dan meluap hasil belajar masih kurang, terbukti ada 39,59\% siswa yang belum menyelesaikan studi dengan katup minimum kampus standart adalah 60.

\section{Abstract}

Background : Midwifery care II is a compulsory subject at study program D3 of midwifery islamic of university of Madura, because it deals directly with the main task of the midwife, is attending births. For that, the learning process of midwifery care II needs special attention, both in term of theory and practice. Objective : The purpose of this study to analyze learning courses of midwifery care II. Method : Design used in this research is descriptive qualitative. Research to be conducted in the from of a single case study with one characteristic (one location). Respondents in this study include student, lectures, and head of study program. In this study there are three kind of data collection analysis. Technical validity of the data with triangulation sources and methode. Techniques used in the analysis process by using interactive analisys model. Result : (1) learning plan is done optimally enough, (2) implementation of learning using of variety of learning methods, (3) evaluations of learning is assesed trough middle test, final test and phase test, (4) contrains encountered in the process of learning that is student interest in learning is less, whereas how to evercome in the learning process are two way communication to determine the dificulty and provide more time for discussion.Conclution : learning process as a whole is less than optimal, because the lack student interest in learning and achivement of learning outcomes is still lacking, it is proved there are $39,59 \%$ of the students who have not completed the study with minimum valve of standart campus is 60 . 


\section{Pendahuluan}

Mata kuliah asuhan kebidanan II merupakan mata kuliah yang sangat penting di Program Studi D3 Kebidanan karena berhubungan langsung dengan tugas utama bidan yaitu menolong persalinan. Untuk itu proses pembelajaran mata kuliah ini perlu perhatian khusus agar nilai yang diperoleh dapat maksimal, yang nantinya akan berpengaruh pada pelaksanaan praktek. Proses pembelajaran meliputi perencanaan, pelaksanaan, dan evaluasi. Dalam proses tersebut juga terdap kendala yang pada akhirnya akan mempengaruhi hasil pencapaian prestasi belajar.

Analisis pembelajaran adalah satu dari beberapa langkah yang harus direncanakan dan dipersiapkan secara matang sebelum kita mentransfer sebuah ilmu kepada siswa. Perlu direncanakan dan dipersiapkan secara matang, karena pada analisis pembelajaran ini terjadi proses menjabarkan perilaku umum menjadi perilaku khusus yang tersusun secara logis dan sistematik (Atwi Suparman, $2001: 89$ ).

Berdasarkan data yang diperoleh dari nilai ujian akhir asuhan kebidanan II dengan jumlah siswa 48 mahasiswa yang tuntas dalam belajar ada $62,5 \%$ dan yang belum tuntas belajar ada $37,5 \%$ dengan KKM yang ditetapkan sekolah adalah 68 . Penelitian ini diupayakan dapat meningkatkan prestasi belajar siswa mencapai $17,5 \%$ sehingga menjadi $80 \%$ yang tuntas.

Tujuan akhir dari proses pembelajaran adalah prestasi belajar yang diperoleh mahasiswa. Menurut teori behaviorisme, belajar adalah perubahan tingkah laku sebagai akibat dari interaksi antara stimulus dan respon atau perubahan yang dialami siswa dalam kemampuannya untuk bertingkah laku dengan cara yang baru sebagai hasil interaksi antara stimulus dan respon. Sedangkan menurut teori humanistik, belajar adalah untuk memanusiakan manusia atau dapat dikatakan proses aktualisasi diri dengan baik. Proses belajar bisa dikatakan berhasil bila seseorang pelajar telah memahami lingkungannya dan dirinya sendiri. Faktor yang berpengaruh di sini adalah penglaman konkrit, pengalaman aktif, dan reflektif, konseptualisasi, dan eksperimentasi seorang pelajar.

Prestasi belajar merupakan hal yang tidak dapat dipisahkan dari kegiatan belajar, karena kegiatan belajar merupakan proses, sedangkan prestasi merupakan hasil dari proses belajar. Prestasi belajar adalah penguasaan pengetahuan atau ketrampilan yang dikembangkan melalui mata pelajaran, umumnya ditujukan dengan nilai yang diberikan oleh guru (Tim Penyusun Kamus Besar Bahasa Indonesia, 2001).

Minat belajar merupakan salah satu modal awal dalam pembelajaran mahasiswa, baik ketika berada di rumah maupun di sekolah. Untuk mewujudkan cita-citanya mahasiswa harus memiliki minat belajar yang tinggi. Minat adalah rasa lebih suka dan rasa ketertarikan pada suatu hal atau aktivitas, tanpa ada yang menyuruh. Sehingga minat itu merupakan suatu dorongan yang timbul karena ada perasaan senang terhadap sesuatu. Minat pada dasarnya adalah suatu penerimaan akan suatu hubungan antara diri sendiri dengan sesuatu diluar diri. Semakin kuat atau dekat hubungan tersebut, semakin besar minatnya. Selain itu minat adalah perasaan ingin tahu, mempelajari, mengagumi dan memiliki sesuatu. Disamping itu minat merupakan bagian dari ranah afeksi, mulai kesadaran sampai pilihan nilai. Holland mengatakan bahwa minat adalah kecenderungan hati yang tinggi terhadap sesuatu (Djaali, 2008).

Temuan yang menarik adalah meskipun dosen cenderung berpartisipasi dalam proses belajar secara optimal, ternyata hasilnya berbeda. Perbedaan tidak hanya pada kondisi guru dan siswa, tetapi ditentukan oleh cara sekolah dalam mengembangkan formula dalam strategi peningkatan mutu. Ada kecenderungan bahwa semakin banyak formula yang dikembangkan oleh kampus, maka akan semakin cepat bagi kampus untuk dapat meningkatkan perbaikan mutu universitas. Untuk mengatasi masalah tersebut dosen 
menggunakan beberapa metode yang variatif agar terjadi komunikasi yang intensif antara mahasiswa dengan mahasiswa lainnya mengenai pokok bahasan yang sedang dibicarakan. Dengan kata lain, terjadi tukar informasi antara mahasiswa yang satu dengan yang lainnya. Hal inilah merupakan salah satu cara untuk meningkatkan perolehan NUA mahasiswa dalam mata kuliah asuhan kebidanan.

Tujuan Penelitian untuk menganalisis Perencanaan pembelajaran Mata Kuliah Asuhan Kebidanan II di Prodi D3 Kebidanan Universitas Islam Madura , Pelaksanaan pembelajaran Mata Kuliah Asuhan Kebidanan II di Prodi D3 Kebidanan Universitas Islam Madura. Evaluasi pembelajaran Mata Kuliah Asuhan Kebidanan II di Prodi D3 Kebidanan Universitas Islam Madura. Kendala atau Faktor-faktor yang menghambat optimalisasi pembelajaran Mata Kuliah Asuhan Kebidanan II dan cara mengatasi. Pencapaian prestasi belajar mahasiswa pada Bpembelajaran Mata Kuliah Asuhan Kebidanan II.

\section{Metodologi}

Penelitian dilakukan di Program studi Kebidanan Universitas Islam Madura, pada bulan April-Mei 2019. Desain Penelitian yang digunakan adalah deskriptif kualitatif. Penelitian yang akan dilakukan dalam bentuk studi kasus tunggal dengan satu karakteristik (satu lokasi). Subjek penelitian yang akan diberikan perlakuan atau tindakan antara lain mahasiswa, dosen, dan ketua program studi. Sumber data diperoleh dari informasi, dokumen, aktivitas, peristiwa dan perilaku. Penelitian ini menggunakan teknik purposive sampling dengan kecenderungan peneliti untuk memperoleh informannya berdasarkan posisi dengan akses tertentu yang dianggap memiliki informasi yang berkaitan dengan permasalahan secara mendalam dan dapat dipercaya untuk menjadi sumber data yang tepat. Pada penelitian ini terdapat tiga macam teknik pengumpulan data, yaitu wawancara, observasi, dan analisis dokumen. Teknik keabsahan data dengan triangulasi sumber dan triangulasi metode. Teknik yang digunakan dalam proses analisis dengan menggunakan model analisis interaktif.

\section{Hasil dan Pembahasan}

Mata kuliah asuhan kebidanan II memberikan kemampuan kepada mahasiswa untuk memberikan Asuhan kebidanan pada ibu dalam persalinan dengan pendekatan manajemen kebidanan didasari konsep konsep, sikap ketrampilan serta hasil evidence based dengan pokok bahasan konsep dasar persalinan, beberapa faktor yang mempengaruhi persalinan, proses adaptasi psikologi dalam persalinan, kebutuhan dasar pada ibu dalam proses persalinan, asuhan pada setiap kala persalinan, deteksi dini komplikasi persalinan dan cara penanganannya, askeb pada bayi segera setelah lahir, cara pendokumentasian asuhan masa persalinan.

Proses pembelajaran mata kuliah asuhan kebidanan II untuk teori dilaksanakan di kelas dengan menggunakan ceramah, diskusi, seminar dan penugasan. Sedangkan untuk praktek dilaksanakan di kelas, laboratorium ( baik di kampus maupun dalam praktek) dengan menggunakan metode simulasi, demontrasi, rote play dan bed side teaching.

Untuk mengevaluasi teori menggunakan prosentase sebagai berikut: UTS : 30\%, UAS : 30\%, Praktikum Skill lab (phantoom) : 40\%.

\section{Perencanaan Pembelajaran Mata Kuliah Asuhan Kebidanan II}

Analisis pembelajaran adalah satu dari beberapa langkah yang harus direncanakan dan dipersiapkan secara matang sebelum kita mentransfer sebuah ilmu kepada mahasiswa. Perencanaan dalam proses pembelajaran dituangkan melalui silabus dan RPP.

Berdasarkan pengumpulan silabus yang sudah terkumpul di bagian akademik, bagian yang ada dalam silabus berupa penjabaran lebih lanjut dari standart kompetensi dan 
kemampuan dasar yang ingin dicapai, dan pokokpokok serta uraian materi yang perlu dipelajari siswa dalam mencapai standart kompetensi dan kompetensi dasar. Dalam silabus juga harus jelas pembagian dosen yang mengampu materi, sehingga dapat mempermudah mahasiswa untuk menghubungi dosen dan sebagai bahan evaluasi untuk pembelajaran semester berikutnya.

Selain silabus perencanaan juga tertuang dalam RPP. Pada hakekatnya RPP merupakan perencanaan jangka pendek untuk memperkirakan atau memproyeksikan apa yang akan dilakaukan dalam pembelajaran. Berdasarkan pernyataan diatas dan hasil wawancara serta hasil observasi tentang kewajiban dosen untuk mengumpulkan RPP merupakan upaya yang dilakukan pihak akademik agar dosen dapat memperkirakan tindakan yang akan dilakukan dalam kegiatan pembelajaran. Dalam RPP juga harus tercantum materi yang akan diajarkan.

\section{Pelaksanaan Pembelajaran Mata Kuliah Asuhan Kebidanan II}

Proses pembelajaran merupakan suatu kegiatan intraksi antara guru dan murid dimana akan diakhiri dengan proses evaluasi hasil belajar (dimyati dan mudjiono, 2006 : 3). Proses pembelajaran juga diartikan sebagai suatu proses terjadinya intraksi antara pelajar, pengajar dalam upaya mencapai tujuan pembelajaran, yang berlangsung dalam suatu lokasi tertentu dalam jangka satuan waktu tertentu pula ( hamalik, 2006 : 162 ).

Berdasarkan pendapat kedua ahli tersebut di atas maka dapat disimpulkan bahwa proses pembelajaran sebagai suatu proses intraksi antara dosen dan mahasiswa dimana akan dikhiri dengan proses evaluasi hasil belajar dalam upaya mencapai tujuan pembelajaran yang berlangsung dalam suatu lokasi dan jangka waktu tertentu. Dosen sebagai pengajar berusaha menciptakan kondisi belajar mahasiswa yang nyaman dan didesain secara sengaja, sistematis dan bersikenambungan.

\section{Evaluasi Pembelajaran Mata Kuliah Asuhan Kebidanan II}

Evaluasi pembelajaran yang dilakukan di Program Studi D3 Kebidanan berupa evaluasi tertulis dan praktik. Untuk teori pengukuran penilaian dilakukan dua kali dalam satu semester yaitu Ujian Tengah Semester (UTS) dan Ujian Akhir Semester (UAS), untuk menunjang maka nilai tugas juga diperhitungkan. Untuk menilai skill atau kompetensi mereka dilakukan praktek di laboratorium untuk persalinan. Mereka dikondisikan seolah-olah menolong persalinan sendiri tetapi menggunakan phantoom. Hal ini ditujukan agar mereka lebih siap sebelum praktik langsung ditengah-tengah masyarakat.

\section{Kendala dalam Proses Pembelajaran Mata Kuliah Asuhan Kebidanan II serta cara mengatasinya}

Pada proses pembelajaran asuhan kebidanan ditemui kendala sebagai berikut sebagian besar mahasiswa mempunyai minat belajar yang rendah, hal ini ditunjukkan dari permasalahan berikut : 1) Apabila guru sedang menjelaskan materi, masih banyak siswa yang berbicara sendiri. 2) Apabila guru bertanya kepada siswa tentang materi yang baru diajarkan, kebanyakan mahasiswa diam saja dan tidak mampu menjawab pertanyaan dosen. 3) Sebagian besar mahasiswa tidak berani bertanya kepada dosen jika mereka belum memahami materi yang diajarkan.

Cara mengatasi kendala tersebut adalah dengan cara Dosen mata kuliah asuhan kebidanan II berusaha untuk mudah bergaul sehingga mahasiswa tidak merasa ketakutan ketika diberi materi perkuliahan dan terjalin komunikasi yang dilakukan antara dosen dengan mahasiswa berjalan dengan rilek dan enjoy seperti halnya "ibu dengan anak". Perhatian yang dilakukan dosen terhadap mahasiswa dengan cara memuji mahasiswa dengan hal-hal yang positif mampu merangsang siswa agar lebih tertarik dalam proses belajar.

\section{Pencapaian Prestasi Mahasiswa pada Mata Kuliah Asuhan Kebidanan II}


Berdasarkan hasil nilai akhir semester yang ada di bagian akademik program studi D3 Kebidanan, masih terdapat 37,5\% mahasiswa yang belum tuntas dalam belajar dengan standart nilai minimum yang ditetapkan kampus adalah 68.

Kondisi ini dipengaruhi oleh berbagai faktor baik dari dosen maupun dari mahasiswa. Minat belajar mahasiswa yang rendah merupakan salah satu faktor yang sangat berpengaruh dalam proses pembelajaran. Karena mahasiswa merupakan pemeran utama dalam penerima informasi atau materi baru. Yang pada akhirnya akan dievaluasi untuk menilai prestasi belajar. Selain itu dosen yang berperan sebagai fasilitator untuk penyampaian materi harus memiliki kemampuan lebih untuk menyampaikan materi agar mahasiswa mampu mengerti penjelasan yang diberikan. Dosen juga harus mampu menjelaskan dengan metode yang variatif, agar mahasiswa tidak merasa jenuh.

\section{Simpulan, Implikasi dan Saran Kesimpulan}

Perencanaan pembelajaran tertuang dalam silabus dan RPP. Pelaksanaan pembelajaran yang dilakukan oleh dosen menggunakan metode yang variatif, namun minat belajar mahasiswa yang rendah membuat pembelajaran kurang kondusif. Evaluasi pembelajaran dinilai dari UTS, UAS dan ujian tahap.

Kendala dalam proses pembelajaran adalah minat belajar mahasiswa yang kurang dan cara mengatasi hambatan tersebut dosen mengajak mahasiswa untuk melakukan komunikasi 2 arah untuk mengetahui kesulitannya dan memberikan waktu lebih untuk berdiskusi. Pencapaian Prestasi Belajar mahasiswa pada pembelajaran mata kuliah asuhan kebidanan II dari segi teori masih terdapat $37,5 \%$ mahasiswa yang belum tuntas dalam belajar. Sedangkan nilai yang dicapai dalam praktek terdapat $37,5 \%$ mahasiswa yang belum tuntas dalam belajar.

\section{Implikasi}

Berdasarkan hasil temuan penelitian yang didapatkan dari observasi langsung, penyebaran kuesioner dan wawancara dari beberapa dosen dan mahasiswa serta ketua program studi D3 Kebidanan maka dapat dijelaskan bahwa proses pembelajaran yang dilaksanakan sudah mengalami peningkatan dan bisa dikatakan sudah memenuhi dalam perencaan pembelajaran dengan menggunakan RPP dan silabus sebagai acuan untuk melaksanakan proses pembelajaran.

Program Studi D3 Kebidanan Universitas Islam Madura telah berusaha meningkatkan mutu dari proses pembelajaran dosen melakukan beberapa metode yang berbeda tergantung kondisi di kelas. Disisi lain mahasiswa yang mempunyai minat belajar yang tinggi ikut berperan aktif untuk kelancaran proses pembelajaran dengan cara membatu teman lain yang mempunyai minat belajar kurang dengan cara belajar bersama.

\section{Saran}

\section{a. Program Studi D3 Kebidanan}

Sebagai upaya peningkatan proses pembelajaran yang bertujuan agar pada saat evaluasi mendapat nilai maksimal. Maka perlu dilakukan pengembangan dosen dengan cara menganjurkan dosen untuk mengikuti pelatihan khususnya yang berhubungan dengan pembelajaran seperti pelatihan pekerti dan AA.

\section{b. Peneliti Selanjutnya}

Perlu dilakukan penelitian yang sejenis, dengan tema pembelajaran yang lebih spesifik misalnya analisis perencanaan dalam proses pembelajaran.

\section{Daftar Pustaka}

Affifudin dan Saebeni A. (2009). Metode

Penelitian Kualitatif. Bandung :

Pustaka Setia.

Alimul,A. (2003). Riset Keperawatan dan

Teknik Penulisan Ilmiah.

Jakarta: Salemba Medika 
. (2007). Metode Penelitian

Kebidanan dan Teknik Analisa

Data. Jakarta: Salemba Medika

Arikunto, S. (2006). Prosedur Penelitian

Suatu Pendekatan Praktek.

Jakarta: Rineka Cipta

Badudu dan Moh. Zain.(1996). Kamus Umum Bahasa Indonesia.

Jakarta: Pustaka Sinar Harapan

Bagian Ilmu Kesehatan Anak FKUI.

(1995). Dasar-dasar

Metodologi Penelitian Klinis.

Jakarta: Bina Pura Aksara

Budi, R. (2008). Memilih Uji Statistik dalam Penulisan Skripsi. Surabaya. Unesa University Press

Conny, S. (1997). Perspektif Pendidikan Anak Bakat. Jakarta: Grasindo

Darmasutapa. (2004). Laporan Penelitian Faktor-faktor yang Mempengaruhi Perbedaan

Prestasi Belajar Murid Kelas V

Sekolah Dasar Sesetan. Bali:

Proyek Pengembangan Ilmu dan

Teknologi

Departemen Pendidikan dan Kebudayaan.

(1998). Kamus Besar Bahasa

Indonesia. Jakarta: Balai

Pustaka

Dimyati dan Mudjiono. (2006). Belajar dan

Pembelajaran. Jakarta: Rineka Cipta.
Gitosudarmo, I dan Mulyono, A. (2007). Teori Motivasi. Diakses 02 April 2012. http://akhmadsudrajat.wordpres s.com

Hakim, T. (2006). Belajar Secara Efektif. Bandung: Niaga Swadaya

Hamalik. (2002). Metode Belajar dan Krsulitan-kesulitan Belajar. Bandung: Tarsito

Hartono. (2004). Statistik untuk Penelitian. Yogyakarta: Pustaka Pelajar Offset

Lie, A. (2004). Memudahkan Anak Belajar. Jakarta: Buku Kompas

Masidjo. (2005). Penilaian Pencapaian Hasil Belajar Siswa di Sekolah. Jakarta: Kanisius

Notoatmodjo, S. (2005). Metodologi Penelitian Kesehatan. Jakarta: Rineka Cipta

Nursalam. (2003). Konsep dan Penerapan Metodologi Penelitian Ilmu Keperawatan. Jakarta: Salemba Medika

Qomariyah, Astutik Nur. 2008. Motivasi. Diakses 12 April 2012. http://anugerawan.blogspot.com Sutopo. (2006). Metode Penelitian Kualitatif. Surakarta : Universitas Sebelas Maret.

Sugiyono. (2010). Metode Penelitian Pendidikan. Bandung: Alfabeta 
(2006). Statistika untuk

Penelitian. Bandung: Alfabeta

Sondang P . (2008). Peningkatan Motivasi.

Diakses 12 April 2012.

http://akhmadsudrajat.wordpres

s.com/

Winkel, WS. (1994). Psikologi Pendidikan

dan Evaluasi Belajar. Jakarta:

Gramedia

Yuliani A. (2008). Proses belajar dan penguasaan materi. Diakses 25 maret 2012 . 